\section{Individual Variations in Rate of Skeletal Maturation}

FRY $^{1}$ recently criticized the Tanner and Whitehouse (TW) method of assessing skeletal maturity ${ }^{2}$ on the grounds that it shows excessive fluctuation in the velocity of maturation. He stated that, in a child whose chronological age advances 6 months, the method may show no advance of skeletal age or, alternatively, a skeletal advance of 23 months. Fry seems to have assigned TW ratings only to the plates in the Greulich-Pyle Atlas, so it is not at all clear how he arrives at the criticism, nor, indeed, precisely what is implied. I am able, however, to supply actual data on the mean rate of maturation of a population of children and on the variation between individual children rated in successive years by the TW method.

The term "velocity" implies a measure of distance travelled in unit time. In terms of skeletal development we may substitute for "distance", "progress towards the maturity of the skeleton". The TW method measures "distance" in this sense by allotting to each of twenty bones, in the hand and wrist, a number of points, according to the progress that bone has made towards its mature state. The unit of "distance" then is the point, and the proper measure of velocity is "points per year".

Velocity must be determined by allotting a score to two radiographs of the same child and dividing the difference between the scores by the time interval (in years or decimals of years) between the dates on which the two radiographs were taken.

This procedure has been applied to children taking part in the London Longitudinal Growth Study. Hand and wrist radiographs, taken within 2 months of each birthday from the fifth to the eleventh, were rated by the TW method. All ratings were made by the same experienced observer, whose consistency has been well established. Accuracy was further ensured by examining consecutively all the radiographs of each child.

\begin{tabular}{|c|c|c|c|}
\hline $\begin{array}{l}\text { Age } \\
\text { (yr) }\end{array}$ & $\begin{array}{l}\text { No. of } \\
\text { subjects }\end{array}$ & $\begin{array}{c}\text { Mean rate } \\
\text { (points/yr*) }\end{array}$ & S.D. \\
\hline $\begin{array}{c}5 \cdot 0-6 \cdot 0 \\
6 \cdot 0-7 \cdot 0 \\
7 \cdot 0-8 \cdot 0 \\
8 \cdot 0-9 \cdot 0 \\
9 \cdot 0-10 \cdot 0 \\
10 \cdot 0-11 \cdot 0\end{array}$ & $\begin{array}{l}54 \\
62 \\
59 \\
49 \\
39 \\
39\end{array}$ & $\begin{array}{l}41 \cdot 0 \\
50 \cdot 5 \\
49 \cdot 9 \\
39 \cdot 9 \\
43 \cdot 4 \\
57 \cdot 7\end{array}$ & $\begin{array}{l}17 \cdot 5 \\
22 \cdot 4 \\
21 \cdot 6 \\
18 \cdot 1 \\
24 \cdot 7 \\
33 \cdot 2\end{array}$ \\
\hline
\end{tabular}

interval between two successive $\mathrm{X}$-rays of each child.

Age
$(\mathrm{yr})$
$5 \cdot 0-6 \cdot 0$
$6 \cdot 0-7 \cdot 0$
$7 \cdot 0-8 \cdot 0$
$8 \cdot 0-9 \cdot 0$
$9 \cdot 0-10 \cdot 0$
$10 \cdot 0-11 \cdot 0$

$\begin{array}{cc}\begin{array}{c}\text { Table 2. } \\ \text { No. of } \\ \text { Nubjects }\end{array} & \begin{array}{c}\text { Mean rate } \\ \text { (points/yr) }\end{array} \\ 54 & 45 \cdot 7 \\ 57 & 48 \cdot 0 \\ 55 & 46 \cdot 2 \\ 51 & 53 \cdot 0 \\ 41 & 70 \cdot 8 \\ 23 & 101 \cdot 3\end{array}$

$S . D$.
$18 \cdot 3$
$20 \cdot 1$
$21 \cdot 2$
$27 \cdot 5$
$41 \cdot 6$
$68 \cdot 6$

* Calculated by dividing increase in number of points by exact time interval between two successive X-rays of each child.

Tables $\mathrm{I}$ and 2 show the means and standard deviations of the velocity of skeletal maturation of boys and girls respectively.

These data can be related to the concept of "skeletal age" by defining one year of advancement in skeletal age as the average number of points gained during the year. On this basis, one year's increase in skeletal age is represented by the mean value in the tables for the year in question and the standard deviation is approximately 6 months in each case. In one year of chronological age, then, a few extreme individuals would show no advance in skeletal age while, at the other extreme, some individuals would advance by the equivalent of about 2 years. The advance of 23 months of "bone age" in 6 months of chronological age that Fry mentions is much beyond the limit observed in our data. Whatever the advance, however, it would be readily detectable and measurable. The average number of points advanced in one year might, of course, vary from one community to another. Average data for a larger number of British children are given by Tanner, Whitehouse and Healy ${ }^{2}$.

The Greulich and Pyle method $^{3}$ does not give any absolute measure of velocity of skeletal maturation and therefore the two methods cannot be compared in the way which Fry suggests. It will be possible to evaluate the Tanner and Whitehouse method fully only when its application to large numbers of subjects in longitudinal studies has shown how accurately it measures their progress towards maturity.

Our studies are being extended to cover a wider range of ages and more detailed interpretation of the data.

Department of Growth and Development, W. A. Marshall

Institute of Child Health,

30 Guilford Street, London WC1.

Received November 18, 1968.

${ }^{1}$ Fry, E. I., Nature, 220, 496 (1968).

${ }^{2}$ Tanner, J. M., Whitehouse, R. H., and Healy, M. J. R., A New System for Estimating Skeletal Maturity from the Hand and Wrist, with Standard Derived from a study of 2,600 Healthy British Children, Parts 1 and 2

${ }^{3}$ Greulich, W. C., and Pyle, S. I., Radiographic Atlas of Skeletal Development of the Hand and Wrist, second ed. (Oxford Univ. Press, Oxford, 1959).

\section{Effects of Sodium Cyclamate on the Growth of Rats compared with other Variations in the Diet}

WE have studied the effects on rats of sodium cyclamate in amounts corresponding to those consumed by man. Male rats were chosen because differences in weight, food consumption and food efficiency (growth per kcalorie of food) are usually more distinet in males than in females. 101 weanling albino rats, divided into six groups, were given a human type diet in a dried and ground form, composed according to the data on the food consumption of the Dutch population in 1961 (refs. 1 and 2). This "Ran-1961" diet was varied by substituting different compounds for bread and potato starch in isocalorically proportionate amounts. The protein lost by replacing potato and bread was resupplied with cooked potato protein and wheat gluten. Sodium cyclamate was substituted for two-thirds of the sugar in the original diet so that the sweetening effect was the same; that is, in an amount $1 / 30$ of the weight of the sugar. The sugar content of the Ran-1961 diet is 15 kcalories per cent.

The six rations are: I, Ran-1961 control; II-V, Ran1961 with 15 kcalories per cent of sugar, butter, sunflower oil and lean dried beef, respectively, instead of starch; VI, Ran-1961-cyclamate, containing $4.26 \mathrm{mg}$ of sodium cyclamate/g of food.

Table 1 gives the weight, gain in weight, food consumption and food efficiency data for a 6 week experimental period. There is little difference between groups I-V, whereas the animals in group VI gained appreciably more weight than any in the other groups. Wilcoxon's parameter-free ranking test ${ }^{3}$ was applied to calculate the bilateral tail errors $\left(P_{2}\right)$. For the difference between group I and group VI, $P_{2}=0 \cdot 01$. The data for consumption of food showed a similar pattern from the first weeks onwards: over 6 weeks $P_{2}=0 \cdot 045$. Even the food efficiency was significantly higher than that of the control group $\left(P_{2}=0.002\right)$.

The only remarkable point in the results from the other groups was the relatively low food consumption-in kcalories - of the animals receiving extra meat, although their weight gain did not differ from that of groups I-IV. Their food efficiency was high, however, and differed significantly from that of the butter and sunflower oil groups $(P=0 \cdot 03)$ though not from the control group. 